\title{
AFE \\ Multi-Objective Optimization of Squeeze Casting Process using Genetic Algorithm and Particle Swarm Optimization
}

\author{
G.C.M. Patel $^{\text {a* }}$, P. Krishna ${ }^{\text {b }}$, P.R. Vundavilli ${ }^{\text {c }}$, M.B. Parappagoudar ${ }^{d}$ \\ ${ }^{a, b}$ Department of Mechanical Engineering, National Institute of Technology Karnataka, Surathkal, India \\ ${ }^{\mathrm{c}}$ School of Mechanical Sciences, Indian Institute of Technology, Bhubaneswar, Odisha, India \\ ${ }^{\mathrm{d}}$ Department of Mechanical Engineering, ChhatrapatiShivaji Institute of Technology, Durg, India \\ *Corresponding author. E-mail address: manju09mpm05@gmail.com
}

Received 21.03.2016; accepted in revised form 07.06.2016

\begin{abstract}
The near net shaped manufacturing ability of squeeze casting process requiresto set the process variable combinations at their optimal levels to obtain both aesthetic appearance and internal soundness of the cast parts. The aesthetic and internal soundness of cast parts deal with surface roughness and tensile strength those can readily put the part in service without the requirement of costly secondary manufacturing processes (like polishing, shot blasting, plating, hear treatment etc.). It is difficult to determine the levels of the process variable (that is, pressure duration, squeeze pressure, pouring temperature and die temperature) combinations for extreme values of the responses (that is, surface roughness, yield strength and ultimate tensile strength) due to conflicting requirements. In the present manuscript, three population based search and optimization methods, namely genetic algorithm (GA), particle swarm optimization (PSO) and multi-objective particle swarm optimization based on crowding distance (MOPSO-CD) methods have been used to optimize multiple outputs simultaneously. Further, validation test has been conducted for the optimal casting conditions suggested by GA, PSO and MOPSO-CD. The results showed that PSO outperformed GA with regard to computation time.
\end{abstract}

Keywords: Squeeze casting process, Multi-objective optimization, Genetic algorithm, Particle swarm optimization and multi-objective particle swarm optimization based on crowding distance (MOPSO-CD).

\section{Introduction}

Metal casting process is considered always to be the most economical route to convert raw materials into finished parts [1]. The near net-shaped manufacturingcapability of the squeeze casting process wasdeveloped by combining the distinguished features of conventional casting (economic and design flexibility) and forging (strength and structural integrity) processes [2]. It is important to note that refined structure, minimum porosity, weldability, heat-treatability, near-net shape manufacture, enhanced mechanical properties, good surface quality, better dimensional accuracy, no runners, feeders and post solidification examinations are the major advantages of squeeze cast processing method [3-5]. It was observed that the product quality in direct squeeze casting wasinfluencedmainly by the structural defects like, oxide inclusions, blistering, under-fill, hot tearing, sticking, cold laps, segregation (v-type, centre line, extrusion) case debonding, porosity and extrusion debonding [6-7].However, appropriate choice of the process variable combinations might eliminate most of the above mentioned defects [7-8]. 
This led the research work directed towards improvement of mechanical and micro-structure properties during 1990s and 2000s. The major class of research work reported across the world during that period was on the use of classical engineering experimental, analytical and numerical approaches. The analytical studies mentioned in [9] were carried out to determine the effects of solidification time on mechanical properties using steady state heat flow and Gracias virtual models. It was observed that shorter solidification resulted in yielding better mechanical properties. The influence of squeeze pressure at varying heat transfer rates on the solidification time were studied using numerical approach [10]. The refined microstructure with smaller dendrite cell size and closer spacing of silicon particles was observed at higher values of squeeze pressure. Moreover, the influence of casting temperature and squeeze pressure on the mechanical properties of the component was studied using classical engineering experimental (varying one parameter at once while keeping other parameters constant) approaches [5, 11-12]. In addition to the said approaches, the influence of casting temperature on mechanical properties was studied in [13] for the fixed die temperature, squeeze pressure and pressure durations. In [14], the effects of squeeze pressure, pouring temperature, die temperature, inoculants, degassing and time delay before pressurization on formation of macro defects with evolution of microstructures were investigated via classical engineering experimental approach. The above approach identified only main effect of the process variables and neglected the interaction factor effects completely. Estimating the interaction effects requires the process parameters need to be simultaneously varied under experimentation. In addition, the authors did not develop a model that could predict the responses without the requirement of actual experiments. To overcome these short comings the statistical modelling tools are developed during recent years.

Modelling is the method of identifying, analyzing and establishing the input-output relationship of a physical system [15]. The modelling of casting and solidification were used for solving various problems like solidification of metal ingots, micro-segregation and simple fluid flow analysis during 1930s1950s [1]. However, these methods are based on the analytical and numerical approaches which are relatively slow and computationally expensive. Later on, Statistical Taguchi method has been used to study the effects of several process variables by varying them simultaneously with minimum number of experiments. The influence of squeeze pressure, pouring and die temperature on surface roughness, tensile strengths, hardness and density of aluminium alloy casting parts were studied using Taguchi method [16 \& 17]. The effects of pressure duration variations are not considered during their analysis. The effects of squeeze pressure, compression holding time, die-materials, casting and die temperature were studied on yield strength, ultimate tensile strengths and hardness using Taguchi method [18 $\& 19]$. The effect of squeeze pressure, die temperature and die materials on surface roughness of LM 13aluminium alloy were studied using statistical Taguchi method [20 \& 21]. It is noteworthy that the experiments were conducted for the fixed pressure duration and pouring temperature. Moreover, the influence of die temperature, squeeze pressure and pressure durations were studied for the fixed pouring temperature on the mechanical properties of non-ferrous alloys [22 and 23]. In [24], the forming pressure, filling velocity, pouring and die temperature influence on mechanical properties were studied using Taguchi method. It is important to note that experiments were conducted for the fixed pressure duration. The key observations that are made from the above literature are as follows: 1) The identified optimal process parameter levels using Taguchi method are not considered to be globally optimal always, 2) Many authors developed models after leaving some of the important parameters and their interaction effects or could not modelled it properly. It is important to note that identifying the extreme values of the responses require the precise relationship between input-output parameters.

The well planned statistical design of experiments (DOE) and response surface methodology (RSM) are used successfully to study the influence of several process parameters by varying them simultaneously. They were studied to provide complete insight on the information related to main, square and interaction effects under those experimental conditions. Two non-linear regressionbased DOE models, such as Box-Behnken Design (BBD) and Central Composite Design (CCD) [25] were used to study the effects of process variables (that is, squeeze pressure, pressure duration, pouring temperature and die temperature) on surface roughness, yield strength and ultimate tensile strengths (UTS) of the cast parts. It is important to note that, the authors derived the response equations expressed as a non-linear function of process variables for each model separately. Further, prediction accuracy of the developed models are compared among themselves with fifteen random test cases. It is interesting to note that, CCD based model performed better for predicting yield strength and surface roughness and BBD model for ultimate tensile strength. Identifying the optimal process variable combinations that could yield minimum surface roughness and higher tensile strengths is of industrial relevance. The conventional methods (that is, Taguchi method, analytical, numerical, conventional engineering experimental, linear, goal, and quadratic programming approaches) might fail to optimize multiple responses, when large number of process variables and their corresponding interaction effects become complex and non-linear in nature. It is also important to note that conventional optimization methods follow the deterministic search procedure with specified rules to move from one solution with respect to other that leads to many suboptimal solutions. To overcome these limitations, nonconventional optimization methods are developed with certain set of probabilistic transition rules to identify the global optimal solutions at many distinct locations in a multi-dimensional space [26]. Moreover, process optimization can be done to either for a single response or multiple responses. The optimal solutions can be clearly determined based on the problem domain (global maxima or minima) for single objective function. Identifying single optimal process variable combinations for surface roughness, yield strength and ultimate tensile strengths is considered to be difficult due to conflicting requirements. Further, the statistical analysis showed that the relationship of the yield and ultimate tensile strength with surface roughness is conflicting in nature. Therefore, this problem requires multi-objective optimization to optimize multiple responses. Multi-objective optimization is the process of optimizing two or more responses (after converting all the responses to form single objective function using suitable mathematical formulation) simultaneously.

Multi-objective optimization can be effectively solved by using non-traditional search techniques such as, ant colony 
optimization, artificial bee colony, bacterial foraging optimization, differential evolution, genetic algorithm, harmonic search, particle swarm optimization, shuffled frog leaping, simulated annealing, teaching learning based optimization and so on. The evolutionary algorithms, such as particle swarm optimization (PSO) and genetic algorithm (GA) determine the optimal solutions through heuristic search mechanisms at many distinct locations in a multi-dimensional space. The concept of identifying the global minima or maxima for the problem domain, using evolutionary computational search mechanisms is first reported by Rosenberg in 1960s [27]. Later on, Schaffer [29] introduced the multi-objective evolutionary computation concept to optimize simultaneously two or more responses. In multiobjective optimization, there are multiple solutions depending on the importance given to the response by the investigator/decision maker. Therefore, the multi-objective optimization can be solved using two general approaches. Two or more responses are combined to form a single composite function after assigning different combination of weights to the objective function, in the first approach. The second approach generates the Pareto solutions depending on the different weights. The weight method was used in the recent past, to resolve different optimization problems in various manufacturing processes, like wire electrical discharge machining [29], tube spinning process [30] and green sand molding process [31]. The present work uses the first approach for identifying the extreme values of different responses through heuristic search mechanisms of GA and PSO. It is important to note that, GA and PSO determines optimal process variable combinations for the extreme values of the responses more quickly through the competitive solutions among the potential populations. In recent past, PSO and GA has been implemented successfully for multi-objective optimization of different manufacturing related problems, such as surface grinding [32], squeeze casting [22], electro chemical machining [33], turning [34] abrasive flow machining [35], surface machining [36] etc. The parameters of evolutionary algorithms are to be modified suitably to successfully handle the multiple objective functions, which are conflict in nature [37]. To determine the best guides for updating both position and velocity of the particles the major modifications are made for simple PSO algorithm [38]. MOPSO-CD method performed better compared to other modification methods like m-DNPSO, CSS-MOPSO, MOPSO and MOPSOCDLS for solving multi-objective optimization problems [39]. The authors [22] attempted to optimize the squeeze casting multiple outputs simultaneously through the response equation derived using statistical Taguchi method via popular genetic algorithm (GA). It is important to note that the derived response equation used for optimization includes only main (linear) effect terms and optimization is conducted for hardness and ultimate tensile strength which does not have conflicting requirements. Further, attempt made by authors [40] to optimize the multiple outputs like density, secondary dendrite arm spacing and hardness of squeeze cast samples using evolutionary algorithms. To the best of authors' knowledge not much work has been reported on surface quality to internal soundness (surface roughness, yield strength and ultimate tensile strength) property optimization of process variables in squeeze casting process.

The response equations derived using two non-linear regression models (that is, $\mathrm{CCD}$ and $\mathrm{BBD}$ ) are used as the objective functions for multi-objective optimization [25]. Three popular evolutionary algorithms such as PSO, MOPSO-CD and GA are used for the said task. The influencing process variables, such as squeeze pressure, pressure duration, pouring temperature and die temperature were considered as inputs, and the responses, namely surface roughness, yield strength and ultimate tensile strengths are treated as objective functions (outputs) for GA, PSO and MOPSO-CD. All objective functions are suitably modified to form a single composite function after assigning different weights for each individual objective function. The validation tests are conducted for the determined optimal process variable combinations for the extreme values of the responses via GA, PSO and MOPSO-CD. Further, GA, PSO and MOPSO-CD prediction performances were compared among themselves with that of experimental values.

\section{Mathematical formulation of the problem}

The casting quality (that is, surface roughness, yield strength and ultimate strength) in squeeze casting process is mainly influenced by the process variables, namely squeeze pressure, pressure duration, pouring temperature and die temperature. The schematic diagram that represents the input-output model of the squeeze casting process is shown in Fig. 1. Selection of appropriate process variables and their corresponding levels prior to development of non-linear models is of paramount importance. Too wide and narrow range of input parameters may result in infeasible solution and incomplete information, respectively about the process for the output function. Therefore, in the present work the choice of process variables and their operating levels are decided after conducting pilot experiments in the research laboratory and available literature (Refer Table 1).

Pressure duration

Squeeze pressure

Pouring temperature

Die temperature

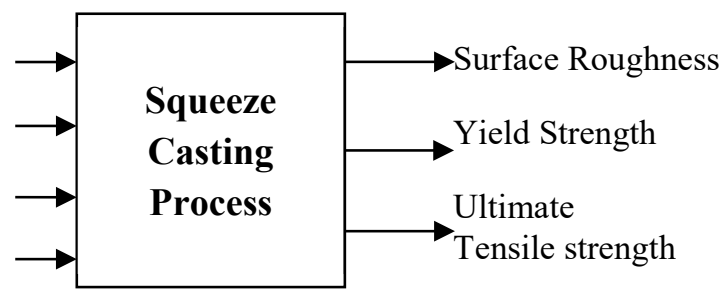

Fig. 1. Input-output model of the squeeze casting process 
Table 1.

Squeeze casting process variables and their operating levels

\begin{tabular}{lccccc}
\hline & Process Parameters & & \multicolumn{2}{c}{ Operating levels } \\
\hline Source & Symbols & Units & Low & Medium & High \\
\hline Pressure Duration, PD & $\mathrm{A}$ & $\mathrm{S}$ & 20 & 35 & 50 \\
Squeeze Pressure, SP & $\mathrm{B}$ & $\mathrm{MPa}$ & 40 & 80 & 120 \\
Pouring Temperature, PT & $\mathrm{C}$ & ${ }^{\circ} \mathrm{C}$ & 630 & 675 & 720 \\
Die Temperature, DT & $\mathrm{D}$ & ${ }^{\circ} \mathrm{C}$ & 150 & 225 & 300 \\
\hline
\end{tabular}

Experiments are conducted for different process variable combinations and operating levels in accordance with the standard experimental matrices of the non-linear (that is, CCD and BBD) models. Three replicates are prepared for each casting conditions to measure the responses such as yield strength, surface roughness and ultimate tensile strength. The prediction performances of the developed models are evaluated for fifteen random experimental test cases [25].It has been observed that CCD based model performed better for predicting yield strength and surface roughness, whereas, BBD model found better for ultimate tensile strength. The predicted best response equations by the non-linear models were used for the said squeeze casting process optimization. The regression equations that represent the casting quality in terms of process variables is shown below.

$$
\begin{aligned}
\mathrm{CCD}_{\mathrm{YS}}= & -1071.38-1.26601 \mathrm{~A}-0.797501 \mathrm{~B}+3.36494 \mathrm{C}+0.902819 \mathrm{D}+0.0123095 \mathrm{~A}^{2}+0.00276227 \mathrm{~B}^{2} \\
& -0.00238537 \mathrm{C}^{2}-8.58733 \times 10^{-4} \mathrm{D}^{2}+0.00253125 \mathrm{AB}+0.000101852 \mathrm{AC}+0.000627778 \mathrm{AD} \\
& +0.000746528 \mathrm{BC}+0.00034375 \mathrm{BD}-8.87037 \times 10^{-4} \mathrm{CD} \\
\mathrm{BBD}_{\mathrm{UTS}}= & -1176.2-4.71685 \mathrm{~A}-1.29458 \mathrm{~B}+3.97148 \mathrm{C}+0.932667 \mathrm{D}-0.00137037 \mathrm{~A}^{2}+0.00234635 \mathrm{~B}^{2} \\
& -0.00293004 \mathrm{C}^{2}-8.21481 \times 10^{-4} \mathrm{D}^{2}+0.00354167 \mathrm{AB}+0.00651852 \mathrm{AC}+4.44444 \times 10^{-5} \mathrm{AD} \\
& \quad+0.00155556 \mathrm{BC}+0.001025 \mathrm{BD}-0.00102693 \mathrm{CD} \\
\mathrm{CCD}_{\mathrm{SR}}= & 15.2320-0.0215093 \mathrm{~A}-0.0249583 \mathrm{~B}-0.0376636 \mathrm{C}+0.00577407 \mathrm{D}+2.22222 \times 10^{-5} \mathrm{~A}^{2} \\
& +6.875 \times 10^{-5} \mathrm{~B}^{2}+2.71605 \times 10^{-5} \mathrm{C}^{2}-8.88889 \times 10^{-6} \mathrm{D}^{2}+2.70833 \times 10^{-5} \mathrm{AB}+2.40741 \times 10^{-5} \mathrm{AC} \\
& -2.22222 \times 10^{-6} \mathrm{AD}+2.08333 \times 10^{-6} \mathrm{BC}+1.08333 \times 10^{-5} \mathrm{BD}-5.92593 \times 10^{-6} \mathrm{CD}
\end{aligned}
$$

The solid thin layer that is formed on the casted aluminium skin may include casting defects larger than that of other microstructure features [41]. Therefore, the surface finish of the cast component is of paramount importance not only in terms of aesthetic appearance, but also forthe proper functionalityof the component during its service life. The near net-shape manufacture ability of the squeeze casting process need to produce the smooth uniform surface with better tensile properties and would not add costly secondary manufacturing processes like, shot blasting, plating, polishing, machining and heat treatment. Therefore, the quality characteristics, such as surface roughness, yield strength and ultimate tensile strength are of industrial relevance to optimize simultaneously with respect to the process variables.

The conflicting objective functions are suitably modified to form a single composite objective function for maximization towards the betterment of casting quality using evolutionary algorithms. To enhance the properties of casting, the responses such as, yield strength and ultimate tensile strength are need to be maximized while minimizing the surface roughness. The statistical analysis and surface plots showed relationship of tensile strengths with the surface roughness are opposite in nature [25].
Therefore, surface roughness is suitably modified for maximization using Eq. [7]. The weighted average method has been employed to form a single composite objective function. The formulated weighted objective function used for maximization is shown below,

Objective function $\left(\mathrm{O}_{1}\right)=$ Yield Strength

Objective function $\left(\mathrm{O}_{3}\right)=1 /$ Surface Roughness

Objective function $\left(\mathrm{O}_{2}\right)=$ Ultimate Tensile Strength

Maximize $\mathrm{Z}=\left(\mathrm{W}_{1} \mathrm{O}_{1}+\mathrm{W}_{2} \mathrm{O}_{2}+\mathrm{W}_{3} \mathrm{O}_{3}\right)$

Subject to constraints

$$
\begin{aligned}
& 20 \leq A \leq 50 \\
& 40 \leq B \leq 120
\end{aligned}
$$


$630 \leq C \leq 720$

$150 \leq D \leq 300$

The terms $\mathrm{O}_{1}, \mathrm{O}_{2}$ and $\mathrm{O}_{3}$ are the objective functions that representyield strength (YS), surface roughness (SR) and ultimate tensile strength (UTS), respectively. A, B, C and D are the process variables representing pressure duration, squeeze pressure, pouring temperature and die temperature, respectively. Moreover, $\mathrm{W}_{1}, \mathrm{~W}_{2}$, and $\mathrm{W}_{3}$ are the weight factors correspond to YS, SR and UTS,respectively. In multi-objective optimization, there exist multiple combinations of optimal solutions corresponding to the value of the weight factors used in the objective function. The weighted fraction for each objective function is assigned based on the requirement of the decision maker. It is important to note that the summation of the weight factors used in the objective function must be equal to one. Further, four different cases studies are selected in such a way that, case 1 deals with equal importance assigned for each individual objective function, followed by maximum importance (cases 2-4) for the response yield strength, surface roughness and ultimate tensile strength, respectively. For the present work four different case studies are considered after assigning different combination of weights. Case $1: \mathrm{W}_{1}=0.3333, \mathrm{~W}_{2}=0.3333$ and $\mathrm{W}_{3}=0.3333$, Case 2: $\mathrm{W}_{1}=0.8, \mathrm{~W}_{2}=0.1$ and $\mathrm{W}_{3}=0.1$, Case 3: $\mathrm{W}_{1}=0.1, \mathrm{~W}_{2}=0.8$ and $\mathrm{W}_{3}=0.1$ and Case $4: \mathrm{W}_{1}=0.1, \mathrm{~W}_{2}=0.1$ and $\mathrm{W}_{3}=0.8$.

\section{Multi-objective optimization}

In the present research work, squeeze cast process parameters are optimized corresponding to the multiple objectives, such as surface roughness, yield strength and ultimate tensile strength of the process using evolutionary computational tools such as GA, PSO and MOPSO-CD. The methodology adopted to optimize the multiple responses simultaneously with the working principle of PSO, MOPSO-CD and GA is discussed in the subsequent sections.

\subsection{Genetic Algorithm (GA)}

Genetic algorithm was introduced to mimic the biological process observed in the natural system over successive generations necessary for evolution. The concept of GA works with the well-known principle of survival of fittest among the potential populations over successive generations, introduced by Prof. John Holland during 1970s at University of Michigan. In recent past, GA has been applied to optimize various classes of real world manufacturing problems [29-32, 35 and 36]. The traditional optimization methods do not guarantee to locate the optimal solution due to their deterministic search mechanisms with certain combination of specified rules to move from one solution with respect to the other. However, randomized heuristic search mechanisms with probabilistic transition rules and adaptive capability help the GA to take many actions simultaneously at different spatial locations for near optimal solution identification. In the present work binary coded GA has been used to optimize the process variables of the squeeze casting process of LM 20 aluminium alloy. The steps followed to formulate the problem and the working cycle with GA is shown in Fig. 2. The tournament selection and bit-wise mutation schemes are used as GA operators and a systematic study has been conducted to identify the best GA parameters (probability of cross over, probability of mutation, population size and maximum generations) to avoid local minima, if any.

\subsection{Particle Swarm Optimization (PSO)}

The particle swarm optimization (PSO) is a population based search algorithm that has implicit parallelism wherein the probability of getting trapped in premature solutions is less. It offers many advantages over conventional optimization tools such as search mechanism uses the probabilistic transition rules, starts search in multi-dimensional space at different spatial locations and no prior knowledge requirement of the initial solution of the problem domain [42]. Few algorithm parameters, easy to implement, fast convergence rate and control over convergence are the major advantages draw much attention towards solving both the continuous and discrete manufacturing problems [30, 31 and 33]. Eberhart and Kennedy introduced the concept of PSO during 1995. Particle swarm optimization mimics the foraging behaviour of the organisms, such as bird flock and fish schooling. In PSO each particle represents the candidate to form a group referred as swarm and all particles change their positions by flying around in multi-dimensional search space at many spatial locations until the computation time exceeds or relatively unchanged positions encountered [43]

The particles adjust their individual fly path by self-flying experience and neighbour particle experiences. In addition each particle keep track on the neighbour particle best solution in the problem domain. In PSO, no evolutionary operators such as cross over and mutations are required. However, PSO use the particles which start with certain velocity and are dynamically adjusted in multi-dimensional search space at many spatial locations. The parameters are iteratively updated for its positions and velocity using Eq. [12] and [13], respectively.

$$
\begin{gathered}
\text { New Velocity }: \mathrm{V}_{\mathrm{i}}^{\mathrm{K}+1}=\mathrm{W} \times \mathrm{V}_{\mathrm{i}}^{\mathrm{k}}+\operatorname{rand}_{1}\left[\text { Pbest }_{\mathrm{i}}^{\mathrm{k}}-\mathrm{P}_{\mathrm{i}}^{\mathrm{k}}\right] \\
+\operatorname{rand}_{2}\left[\text { Gbest }_{\mathrm{i}}^{\mathrm{k}}-\mathrm{P}_{\mathrm{i}}^{\mathrm{k}}\right]
\end{gathered}
$$

The term inertia weight (W) is a parameter that controls the impact of previous velocities on the current velocity. However for initial search, higher inertia weight is recommended to enhance the global search capabilities, while low inertia weight for the final stage during local search. $\mathbf{V}_{\mathrm{i}}^{\mathrm{k}}$ is the current velocity of the individual particle $\mathrm{i}$ at iteration $\mathrm{k}, \mathrm{V}_{\mathrm{i}}^{\mathrm{K}+1}$ is the iterative update velocity of the individual particle $\mathrm{i}$ at iteration $\mathrm{k}+1, \operatorname{rand}_{1}$ and 
rand $_{2}$ are the random numbers distributed uniformly in the range between zero and one. Pbest ${ }_{i}^{k}$, Gbest $t_{i}^{k}$ depicts the best positions of individual particle $i$ have reached and group until iteration k respectively. The second term in Eq. 12 refers to cognitive part, wherein the particle change velocity with self-experience and the third term (social part) adjust the particle velocity through their neighboring particle experience. The methodology employed in identifying the optimal variable combinations responsible for extreme response values and working cycle of PSO is illustrated in Fig. 2.

\subsection{Multi-objective particle optimization with crowding distance}

swarm

MOPSO-CD method is associated with the evolutionary operator namely, mutation that is introduced in the simple PSO to maintain the different class of non-dominated solution in an external achieve [43]. In MOPSO-CD, mutation operator is used to avoid the premature convergence (local solutions) by widening the search space, when the initial population (swarm size) is not sufficient [43]. The cognitive leader ( Pbest) and social leader ( Gbest) are selected in MOPSO-CD based on the Pareto dominance and crowding distance methods. Therefore, MOPSO$\mathrm{CD}$ is considered as an excellent tool to map the complex multiple conflicting response functions for optimization. The working cycle of MOPSO-CD method is shown schematically in Fig. 3.

\section{Results and Discussions}

The results of parametric study that is used for the optimization of the algorithms, and the optimal process variable combinations that are obtained for four case studies are discussed in the following sections.

\subsection{Genetic Algorithm}

The genetic algorithm is capable of identifying the potential solutions responsible for better surface quality and mechanical properties of cast component. In multi-response optimization, the quality performance characteristic depends mainly on the weight factors assigned for each response. In the present study, three conflicting responses are chosen for optimization. Further, four different case studies are considered after assigning different combination of weights. It is important to note that identifying near optimal solutions for the problem domain using GA rely mainly on the appropriate choice of GA parameters, such as probability of cross over $\left(\mathrm{P}_{\mathrm{C}}\right)$, probability of mutation $\left(\mathrm{P}_{\mathrm{M}}\right)$, population size (Pop. Size) and maximum number of generations (Gen). There are no global acceptable standards available for selection of GA parameters. Therefore, the optimal GA parameters are determined using the parametric study by varying one parameter at a time and keeping rest at the fixed values (see Fig. 4). In the first stage of GA parametric study, probability of cross over $\left(\mathrm{P}_{\mathrm{C}}\right)$ is varied in the range between $0.5-1$ to identify the maximum fitness value after keeping the values of probability of mutation, population size and generation number fixed at $0.15,80$ and 100 , respectively. The optimized probability of cross over $\left(\mathrm{P}_{\mathrm{C}}{ }^{*}\right)$ for the maximum fitness value is found equal to 0.7 (see Fig. 4 (a)). Therefore for the second stage and further the $\mathrm{P}_{\mathrm{C}}$ is kept equal to 0.7, and determined the maximum fitness values for $\mathrm{P}_{\mathrm{M}}$, Pop. Size and Gen. The optimized GA parameters responsible for maximum fitness values determined using the parameter study is shown below,

Probability of crossover $\left(\mathrm{P}_{\mathrm{C}}{ }^{*}\right)=0.7$

Probability of mutation $\left(\mathrm{P}_{\mathrm{M}}{ }^{*}\right)=0.15$

Population size (Pop. Size $\left.{ }^{*}\right)=130$

Generation number $\left(\mathrm{Gen}^{*}\right)=90$

The maximum fitness values obtained for the optimal casting conditions obtained for case 1 to case 4 is found to be equal to $122.8,138.2,38.25$ and 193.6, respectively. The optimum casting conditions for the multiple outputs obtained for different weight factor combinations is showed in Table 2. Since the performed multi-objective optimization is done for maximization and the case 4 is recommended as their corresponding maximum fitness value found to be greater than other case studies, considered to give lower surface roughness and higher tensile strength values. 


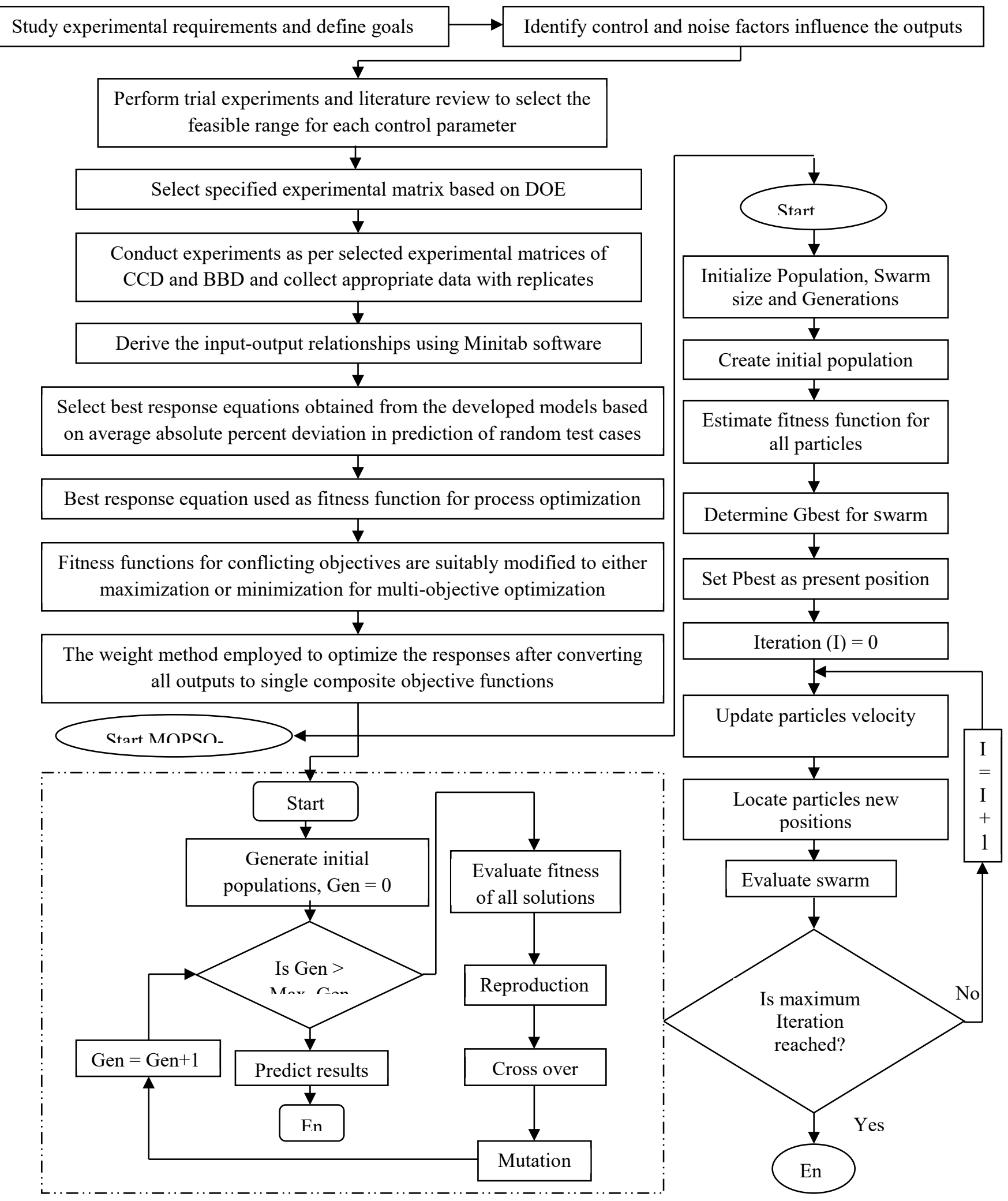

Fig. 2. Methodology formulation with working cycle of GA nd PSO 


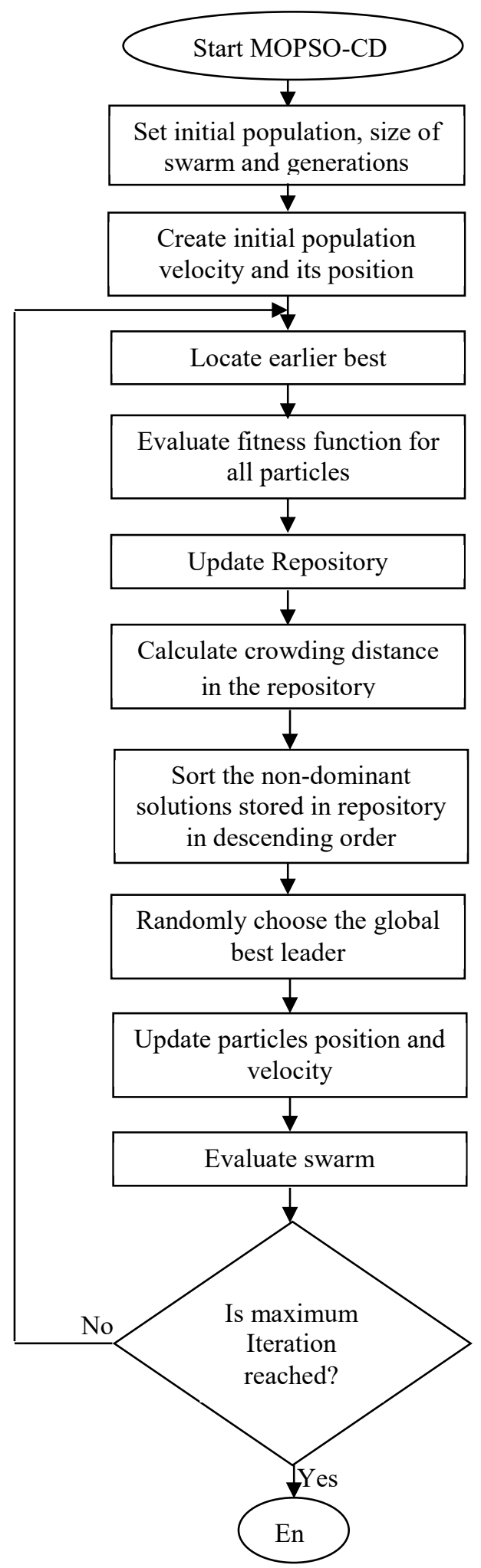

Fig. 3. The working cycle of MOPSO-CD

Table 2. 
Optimum casting conditions for multiple outputs with different combination of weight factors via GA

\begin{tabular}{lcccc}
\hline \multirow{2}{*}{$\begin{array}{c}\text { Process } \\
\text { variables }\end{array}$} & \multicolumn{4}{c}{ Optimum values of casting conditions and casting properties } \\
\cline { 2 - 5 } \& Outputs & $\begin{array}{c}\text { Case } 1 \\
\left(\mathrm{~W}_{1}=0.333, \mathrm{~W}_{2}=0.333\right. \\
\left.\text { and } \mathrm{W}_{3}=0.333\right)\end{array}$ & $\begin{array}{c}\text { Case } 2 \\
\left(\mathrm{~W}_{1}=0.8, \mathrm{~W}_{2}=0.1 \text { and } \mathrm{W}_{3}\right.\end{array}$ & $\begin{array}{c}\text { Case } 3 \\
\left(\mathrm{~W}_{1}=0.1, \mathrm{~W}_{2}=0.8 \text { and }\right. \\
\left.\mathrm{W}_{3}=0.1\right)\end{array}$ & $\begin{array}{c}\text { Case } 4 \\
\left(\mathrm{~W}_{1}=0.1, \mathrm{~W}_{2}=0.1\right. \\
\left.\text { and } \mathrm{W}_{3}=0.8\right)\end{array}$ \\
\hline $\mathrm{A}: \mathrm{PD}, \mathrm{sec}$ & 49.87 & $=0.1)$ & 49.95 & 49.97 \\
$\mathrm{~B}: \mathrm{SP}, \mathrm{MPa}$ & 119.51 & 49.94 & 119.98 & 119.06 \\
$\mathrm{C}: \mathrm{PT},{ }^{\circ} \mathrm{C}$ & 709.84 & 119.51 & 706.29 & 719.81 \\
$\mathrm{D}: \mathrm{DT},{ }^{\circ} \mathrm{C}$ & 201.17 & 691.35 & 21.06 & 193.79 \\
$\mathrm{SR}, \mu \mathrm{m}$ & 0.550 & 210.27 & 0.534 & 0.570 \\
$\mathrm{YS}, \mathrm{MPa}$ & 143.7 & 0.529 & 144.3 & 142.2 \\
$\mathrm{UTS}, \mathrm{MPa}$ & 223.2 & 144.9 & 223.2 & 224 \\
\hline
\end{tabular}
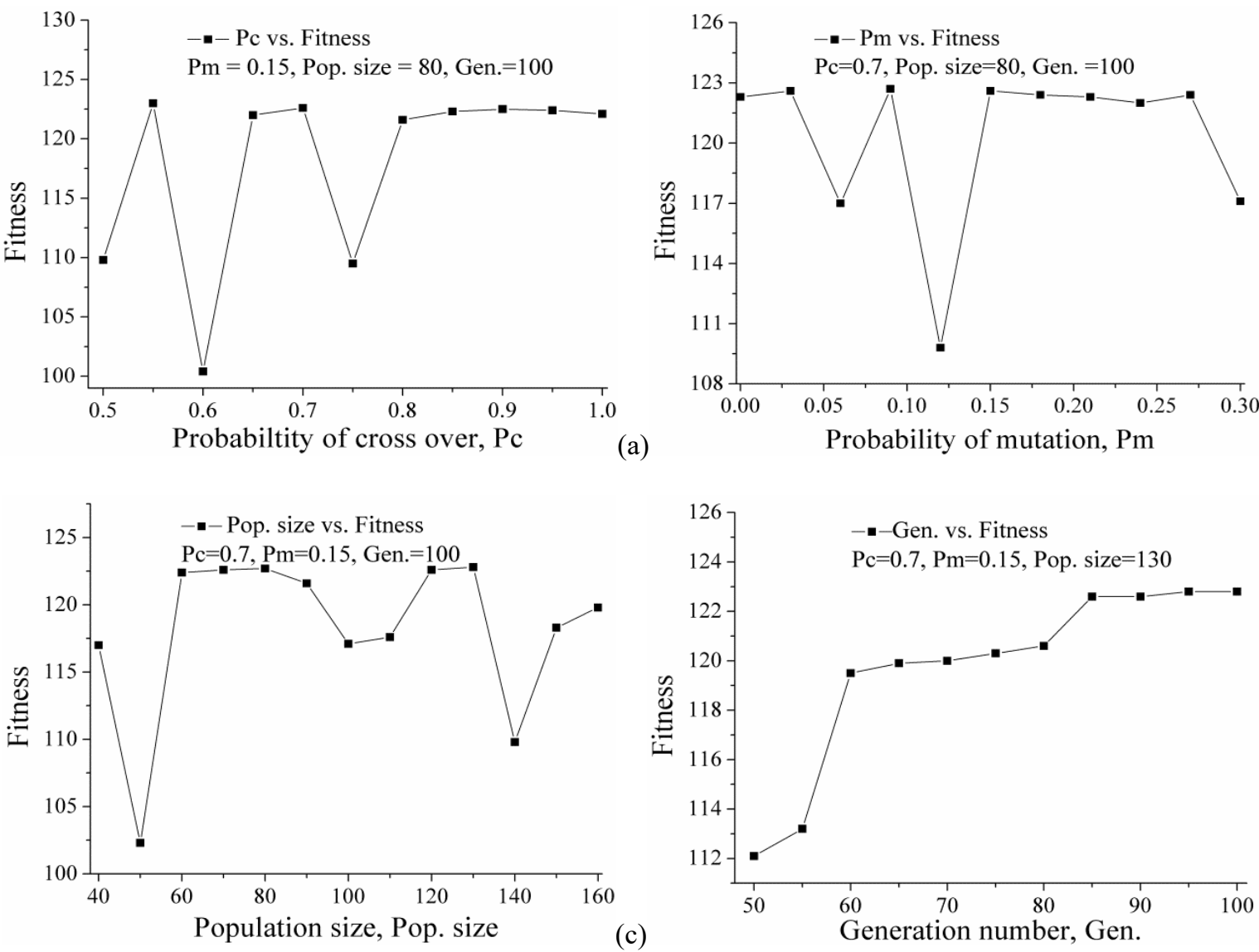

(b)

Fig. 4. GA parametric study: (a) Fitness vs. Probability of crossover (Pc), (b) Fitness vs. Probability of mutation (Pm), (c) Fitness vs. Population size and (d) Fitness vs. Generation number

\subsection{Particle Swarm Optimization}

PSO is also a population based search algorithm that is used to identify the optimal casting conditions. It is important to note that the optimal values of the process depend on the parameters of PSO, such as best values of inertia weight, swarm size and number of generations. The swarm size in particle swarm optimization decides the computational time to locate the optimal solutions. Larger swarm size has more probability to identify the global solutions than with smaller swarm size. Moreover, smaller swarm size has greater susceptibility to get trapped at local minima solutions. As discussed in the earlier section no universal standards are reported for the identification of optimal parameters of PSO. Therefore, a systematic study has been conducted by varying one parameter at a time after keeping the rest as constant (see Fig. 5). Initially, the inertia weights (W) are varied in the range between zero and one, after keeping both the swarm size and number of generations fixed at 50. The optimized inertia 
weight $\left(\mathrm{W}^{*}\right)$ corresponding to the maximum fitness value is seen to be equal to 0.3 (see Fig. 5 (a)). This value is further used for identifying the optimum swarm size (SS ${ }^{*}$ ) and maximum number of generations $\left(\mathrm{Gen}^{*}\right)$. The optimized values of PSO parameters that represent the better casting quality are shown below,

Inertia weight $\left(\mathrm{W}^{*}\right)=0.3$

Swarm size $\left(\mathrm{SS}^{*}\right)=50$

Number of generations $\left(G^{*}\right)=60$
In this case also, the same four case studies that explained in the earlier section are considered. The maximum fitness values obtained for Case 1 through4 are found to be equal to 122.8 , 138.1, 38.23 and 193.6, respectively. From the result, it has been observed that Case 4 of PSO algorithm has outperformed the other cases to give low values of surface roughness and higher tensile strengths. Table 3 shows the optimum casting conditions determined for multiple responses with different combination of weight factors.

Table 3.

Optimum casting conditions for multiple outputs with different combination of weight factors via PSO

\begin{tabular}{lcccc} 
& \multicolumn{4}{c}{ Optimum values of casting conditions and casting properties } \\
\cline { 2 - 5 } $\begin{array}{c}\text { Process variables } \\
\text { \& Outputs }\end{array}$ & $\begin{array}{c}\text { Case } 1 \\
\left(\mathrm{~W}_{1}=0.333, \mathrm{~W}_{2}=0.333 \text { and }\right. \\
\left.\mathrm{W}_{3}=0.333\right)\end{array}$ & $\begin{array}{c}\text { Case } 2 \\
\left(\mathrm{~W}_{1}=0.8, \mathrm{~W}_{2}=0.1 \text { and }\right. \\
\left.\mathrm{W}_{3}=0.1\right)\end{array}$ & $\begin{array}{c}\text { Case } 3 \\
\left(\mathrm{~W}_{1}=0.1, \mathrm{~W}_{2}=0.8 \text { and }\right. \\
\left.\mathrm{W}_{3}=0.1\right)\end{array}$ & $\begin{array}{c}\text { Case } 4 \\
\left(\mathrm{~W}_{1}=0.1, \mathrm{~W}_{2}=0.1\right. \\
\left.\text { and } \mathrm{W}_{3}=0.8\right)\end{array}$ \\
\hline $\mathrm{A}: \mathrm{PD}, \mathrm{sec}$ & 49.32 & 49.84 & 49.44 & 49.48 \\
$\mathrm{~B}: \mathrm{SP}, \mathrm{MPa}$ & 119.78 & 119.99 & 119.79 & 119.49 \\
$\mathrm{C}: \mathrm{PT},{ }^{\circ} \mathrm{C}$ & 710.23 & 704.95 & 691.43 & 716.99 \\
$\mathrm{D}: \mathrm{DT},{ }^{\circ} \mathrm{C}$ & 210.29 & 212.86 & 214.68 & 198.44 \\
$\mathrm{SR}, \mu \mathrm{m}$ & 0.539 & 0.536 & 0.524 & 0.559 \\
YS, $\mathrm{MPa}$ & 143.5 & 143.8 & 144.8 & 142.6 \\
$\mathrm{UTS}, \mathrm{MPa}$ & 223.4 & 223.6 & 220.5 & 223.2 \\
\hline
\end{tabular}

\subsection{Multi Objective Particle Swarm Optimization - Crowding Distance}

Here also, a parametric study has been conducted to determine the optimum evolutionary operator that is mutation and PSO parameters (that is, inertia weight, swarm size and generations). The best parameters responsible for maximum fitness values determined after conducting the detailed parameter study (refer Fig. 6) is as follows,

Probability of Mutation $\left(\mathrm{P}_{\mathrm{M}}{ }^{*}\right)=0.21$

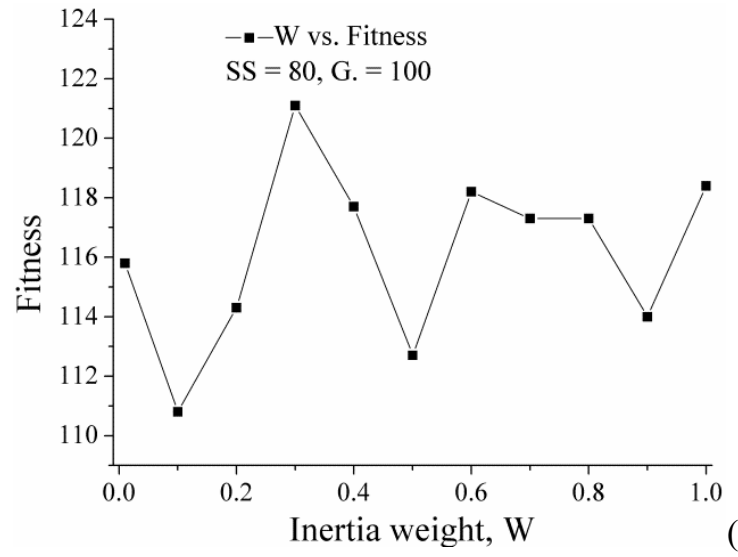

Inertia Weight $\left(\mathrm{W}^{*}\right)=0.1$

Swarm Size $\left(\mathrm{SS}^{*}\right)=50$

Number of Generations $\left(\mathrm{G}^{*}\right)=40$

The extreme values of the conflicting objective functions and their associated process variable combinations are presented in Table 4. It is noteworthy that the fitness values as obtained for case 1 to case 4 are found equal to $123.1,138.4,38.17$ and 194.1, respectively. Furthermore, for MOPSO-CD the case 4 is considered to be the best, as their associated process variable set are responsible for the maximum fitness values.

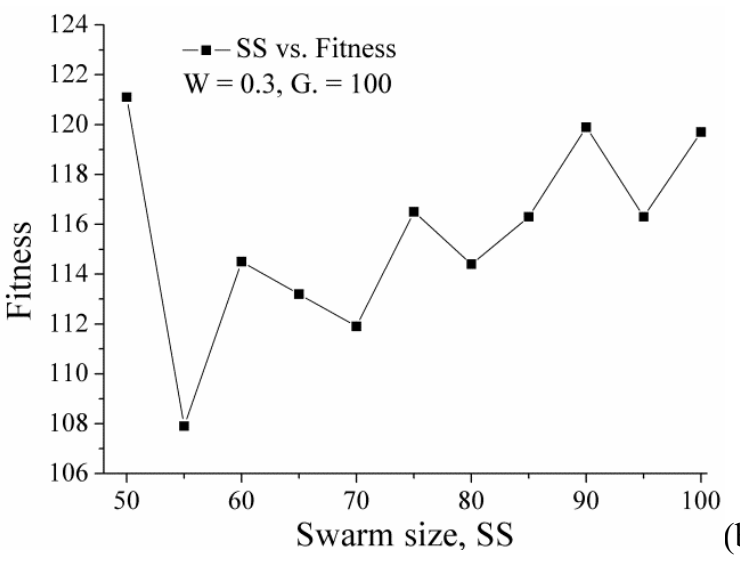




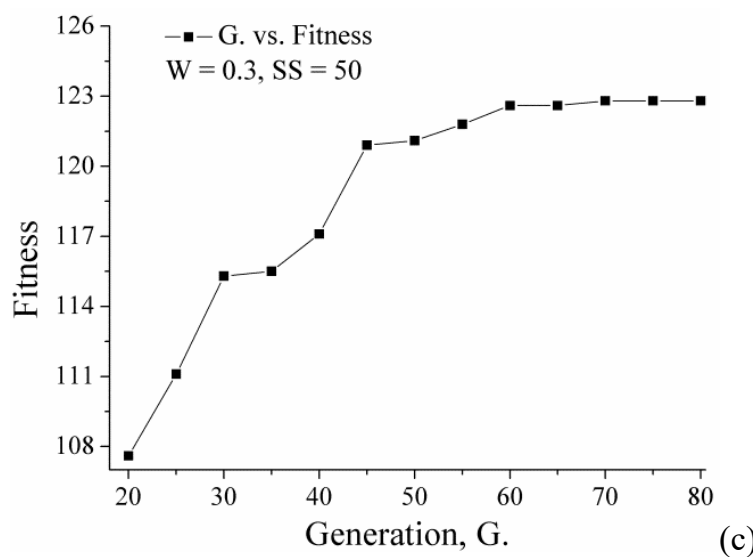

Fig. 5. Particle swarm optimization (PSO) parametric study: (a) Fitness vs. Inertia weight, (b) Fitness vs. Swarm size and (c) Fitness vs. Maximum generations

Table 4.

Optimum casting conditions for multiple outputs with different combination of weight factors via MOPSO - CD

\begin{tabular}{|c|c|c|c|c|}
\hline \multirow[b]{2}{*}{$\begin{array}{l}\text { Process variables } \\
\text { \& Outputs }\end{array}$} & \multicolumn{4}{|c|}{ Optimum values of casting conditions and casting properties } \\
\hline & $\begin{array}{c}\text { Case } 1 \\
\left(\mathrm{~W}_{1}=0.333, \mathrm{~W}_{2}=0.333 \text { and }\right. \\
\left.\mathrm{W}_{3}=0.333\right)\end{array}$ & $\begin{array}{c}\text { Case } 2 \\
\left(\mathrm{~W}_{1}=0.8, \mathrm{~W}_{2}=0.1 \text { and }\right. \\
\left.\mathrm{W}_{3}=0.1\right)\end{array}$ & $\begin{array}{c}\text { Case } 3 \\
\left(\mathrm{~W}_{1}=0.1, \mathrm{~W}_{2}=0.8 \text { and }\right. \\
\left.\mathrm{W}_{3}=0.1\right)\end{array}$ & $\begin{array}{c}\text { Case } 4 \\
\left(\mathrm{~W}_{1}=0.1, \mathrm{~W}_{2}=0.1\right. \\
\left.\text { and } \mathrm{W}_{3}=0.8\right)\end{array}$ \\
\hline A: PD, sec & 49.99 & 49.95 & 49.94 & 49.95 \\
\hline $\mathrm{B}: \mathrm{SP}, \mathrm{MPa}$ & 119.99 & 119.96 & 119.98 & 119.96 \\
\hline $\mathrm{C}: \mathrm{PT},{ }^{\circ} \mathrm{C}$ & 709.52 & 692.87 & 695.48 & 718.26 \\
\hline D: DT, ${ }^{\circ} \mathrm{C}$ & 199.16 & 208.26 & 211.06 & 195.05 \\
\hline $\mathrm{SR}, \mu \mathrm{m}$ & 0.548 & 0.529 & 0.527 & 0.563 \\
\hline $\mathrm{YS}, \mathrm{MPa}$ & 144.0 & 145.1 & 145.1 & 142.9 \\
\hline UTS, MPa & 223.7 & 220.9 & 221.5 & 224.5 \\
\hline
\end{tabular}

\subsection{Confirmation Test}

Experiments have been conducted to determine the response values with the optimum values of parameters obtained in MOPSO-CD. The experiments conducted for case 4 of MOPSO$\mathrm{CD}$ is having higher fitness value as compared to other case studies. It is to be noted that, the experiments have been conducted under similar condition as those used to develop CCD and BBD model (refer Table 5). Surface roughness, yield strength and ultimate tensile strengths are measured in accordance with test methods, JIS 2001 and ASTM E8 standards. High yield strength and ultimate tensile strength, with low surface roughness values are obtained for the optimum casting conditions suggested by MOPSO-CD. The ability of evolutionary algorithms to yield best process variable combinations in a complex input-output relation is found to be very good. High squeeze pressure forces the melt close to die surface walls, thereby improves the surface finish, rate of heat extraction and alters microstructure which will result in better yield and ultimate tensile strength. Pressure duration is found to have negligible influence on the quality of squeeze cast parts, when it is varied between the respective boundary conditions [25]. It is to be noted that, beyond the suggested (required) squeeze pressure and duration have found negligible improvement on casting properties. On the other-hand they affect the die life and require high tonnage equipment facility
[4 and 7]. The impact of die temperature to improve casting properties is found to be more as compared to pouring temperature [25]. Low and high die temperatures are not desirable in squeeze casting process due to premature solidification and high cycle time (that is, rate of heat extraction decreases), respectively. The aforementioned reasons resulted in relatively fine size particles with refinement of eutectic silicon particles on the inter-granular fracture surface (refer Fig. 7). The microstructure explained above, results in a better tensile strength property.

\subsection{Comparison of PSO, MOPSO-CD and GA}

The results obtained from three non-traditional evolutionary algorithms, such as GA, PSO and MOPSO-CDare compared in terms of identification of extreme values of multiple outputs responsible for better casting quality. The optimum locations are identified by all the evolutionary algorithms accurately in multidimensional space at many spatial locations simultaneously. It is interesting to note that all evolutionary algorithms recommended the case 4 , as their corresponding maximum fitness value is found to be greater than the rest all case studies considered for investigation. 

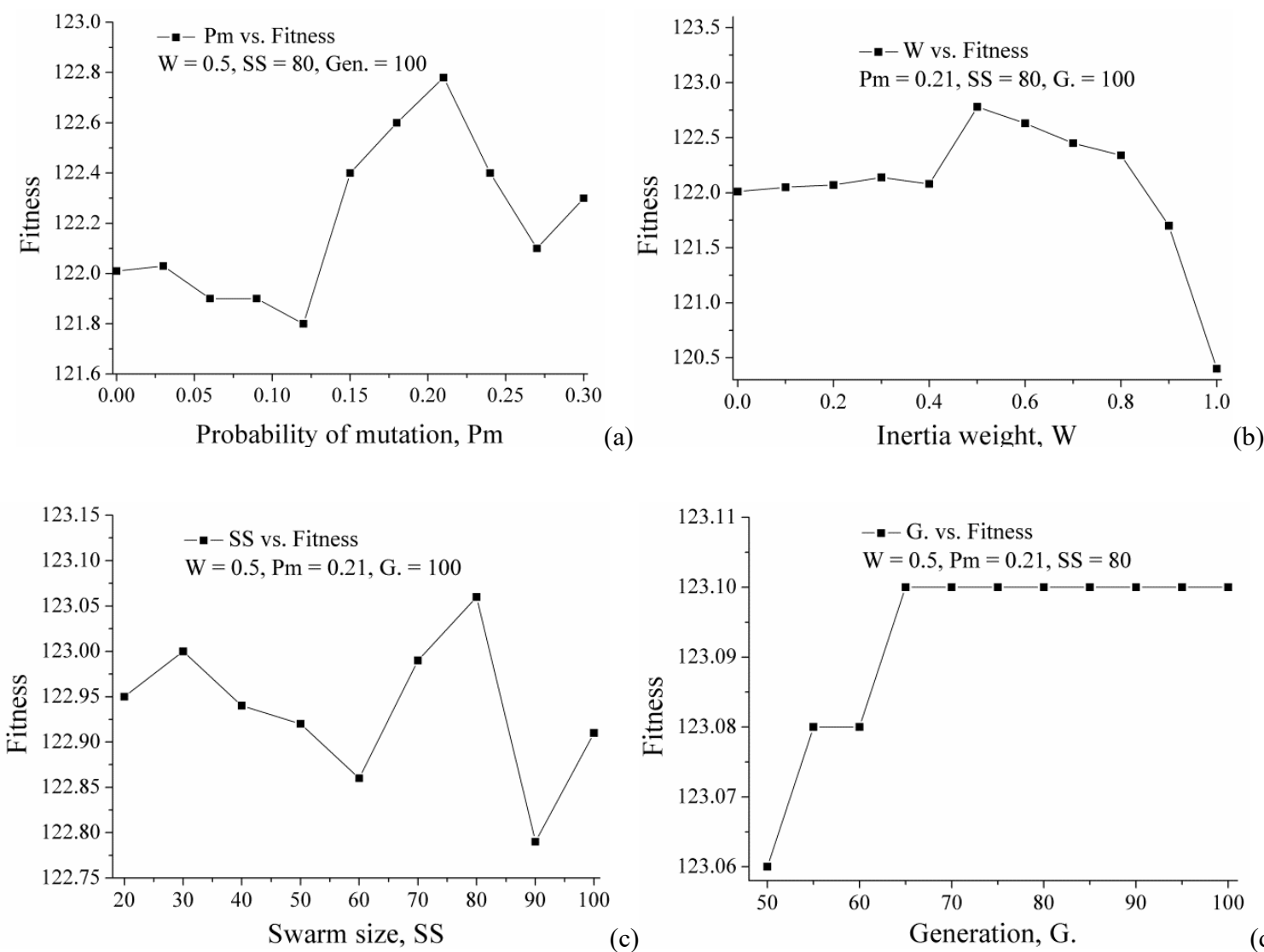

Fig. 6. MOPSO-CD parametric study: (a) Fitness vs. Probability of mutation, (b) Fitness vs. Inertia weight, (c) Fitness vs. Swarm size and (d) Fitness vs. Maximum generations

Table 5.

Results of confirmation test for the optimal casting conditions

\begin{tabular}{cccccccc}
\hline & \multicolumn{3}{c}{ Optimal process variables } & \multicolumn{2}{c}{ Responses } \\
\cline { 2 - 7 } Algorithm & $\begin{array}{c}\text { Pressure } \\
\text { duration, s }\end{array}$ & Squeeze pressure, MPa & Pouring temperature, ${ }^{\circ} \mathrm{C}$ & $\begin{array}{c}\text { Die } \\
\text { temperature, }{ }^{\circ} \mathrm{C}\end{array}$ & SR, $\mu \mathrm{m}$ & YS, MPa & $\begin{array}{c}\text { UTS, } \\
\mathrm{MPa}\end{array}$ \\
\hline MOPSO-CD & 50 & 120 & 718 & 195 & 0.52 & 144.8 & 229.4 \\
\hline
\end{tabular}
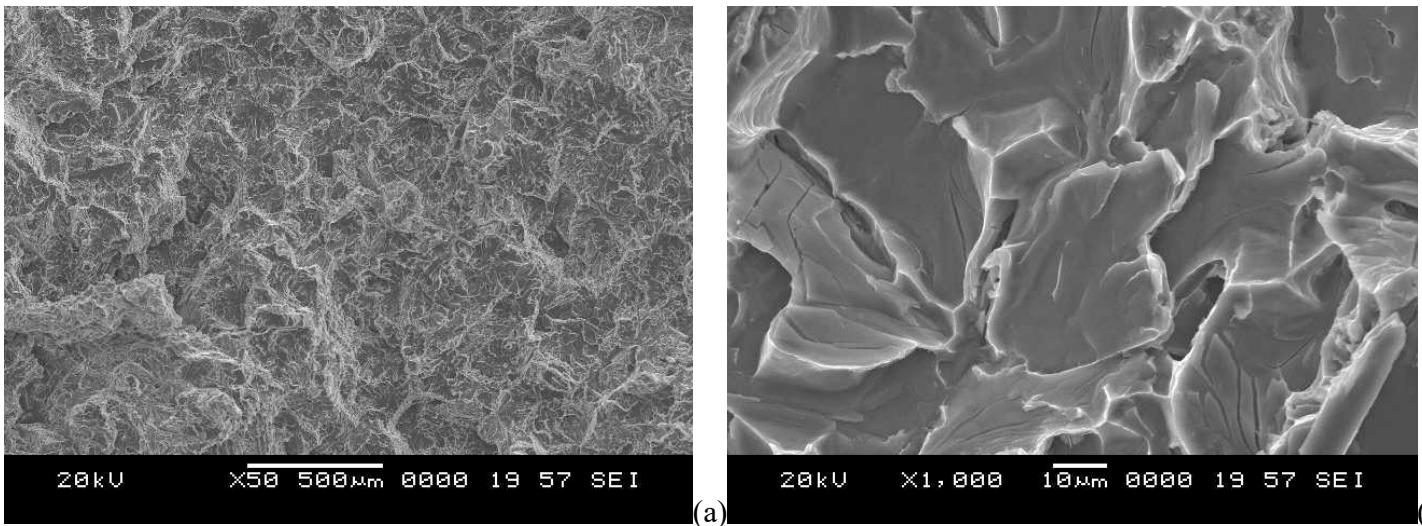

Fig. 7. Scanning electron micrographs of tensile fracture surface obtained for optimum casting conditions recommended by MOPSO-CD: (a) Low Magnification and (b) High magnification 
The maximum fitness values as obtained for case 4 using GA, PSO and MOPSO-CD are found to be equal to 193.6, 193.6 and 194.1, respectively. MOPSO-CD located the extreme response values with higher fitness and found to give better performance when compared with that of GA and PSO. The recommended process variable combinations are tested under experimental conditions to confirm the optimal locations determined by MOPSO-CD. Prior to confirmation experiments the parameters of evolutionary algorithms are optimized by conducting systematic study (that is, varying one parameter at once after keeping the rest at fixed value). The systematic study is of prior importance not only in terms of convergence speed, but also to avoid local minima (if any). The optimized GA parameters such as probability of cross over $\left(\mathrm{P}_{\mathrm{C}}{ }^{*}\right)$, probability of mutation $\left(\mathrm{P}_{\mathrm{M}}{ }^{*}\right)$, population size (Pop $\left.{ }^{*}\right)$ and number of generations $\left(\mathrm{Gen}^{*}\right)$ are found to be equal to $0.7,0.15,130$, and 95 , respectively. The optimized PSO parameters such as inertia weight $\left(\mathrm{W}^{*}\right)$, swarm size $\left(\mathrm{SS}^{*}\right)$ and number of generations $\left(\mathrm{G}^{*}\right)$ are found to be equal to $0.3,50$ and 70 respectively. Similarly, the optimized MOPSO-CD parameters namely, $\mathrm{P}_{\mathrm{M}}{ }^{*}, \mathrm{~W}^{*}, \mathrm{SS}^{*}$ and $\mathrm{G}^{*}$ are found equal to 0.21 , $0.5,80$, and 65 , respectively. It is important to note that the speed of convergence in terms of number of generations to locate the optimal values is found equal to 70 for PSO, 65 for MOPSO-CD and 95 for GA, respectively. This indicates the faster rate of convergence observed with regard to computation time using PSO than GA. Further, the confirmation test conducted for the recommended case 4 by the evolutionary algorithms are compared in terms of percent deviation. The percent deviation associated with surface roughness, yield strength and ultimate tensile strength are found equal to $8.35 \%, 3.97 \%$, and $2.14 \%$ for MOPSO$\mathrm{CD}, 9.65 \%, 4.43 \%$, and $2.36 \%$ for GA and $7.67 \%, 4.17 \%, 2.70 \%$ for PSO, respectively. The average absolute percent deviation for all responses when compared to experimental values is found equal to $4.82 \%, 5.48 \%$ and $4.85 \%$ for MOPSO-CD, GA and PSO, respectively. The results showed that all the evolutionary algorithms identified the extreme values of the responses for the global process variable combinations accurately. However, PSO performed better in terms of computational time to reach the maximum fitness value with the number of generations. The better computation time of PSO might be due to the exhaustive search carried out in multi-dimensional space at many distinct spatial locations with simple structure and few tuning parameters.

\section{Concluding Remarks}

In the present manuscript, an attempt is made to simultaneously optimize the multiple responses (that is, surface roughness, yield strength and ultimate tensile strengths) of a casting component that could put it in service immediately without the requirement of costly secondary manufacturing processes. Evolutionary algorithms offer greater advantage like general adaptability for wide range of problem domains, ease of implementation and no prior knowledge requirement of the initial search space of the problem. Therefore, three evolutionary algorithms, namely GA, PSO and MOPSO-CD are used to optimize the input-output variables of the squeeze casting process. The best response equations representing the function of process variables derived through non-linear models (that is, CCD and BBD) are used as the fitness function for the evolutionary algorithms. The conflicting (two responses are of maximization type and one response is minimization type) objectives of the present problem is solved after converting it into a single objective function for maximization with different combination of weights. All the evolutionary algorithms (that is, PSO, MOPSO-CD and GA) determined the optimal process variable combinations for extreme values of the responses. Confirmation experiments are conducted for the identified optimal process variable combinations corresponding to the observed maximum fitness values obtained under different case studies. The results showed that all the algorithms are effectively capable of identifying the optimal process variable combination for the extreme values of responses. However, MOPSO-CD and PSO outperformed GA with regard to computation time to reach the maximum fitness value corresponding to the number of generations. Improved performance of the particle swarm optimization might be due to simple structure and few tuning parameters. It is important to mention that the present research work is of much industrial relevance, since the determined optimal values of the process variables are capable of yielding better surface quality and internal casting strengths for the single process variable combination. The shortcomings of the existing approaches (like, casting simulation software, numerical, analytical and traditional experimental approaches) are overcome after using these evolutionary algorithms and this approach helped in determining the optimal process variable combinations responsible for enhanced casting properties.

\section{Acknowledgement}

The authors wish to thank the Department of Applied Mechanics \& Hydraulics, National Institute of Technology Karnataka, India, for their kind cooperation in carrying out the experiments.

\section{References}

[1] Kuang-Oscar, Yu. (2001). Modeling for casting and solidification processing. CRC Press.

[2] Vijian, P., Arunachalam, V.P. \& Charles, S. (2007). Study of surface roughness in squeeze casting LM6 aluminium alloy using Taguchi method. Indian Journal of Engineering \& Materials Sciences. 14, 7-11.

[3] Ghomashchi, M.R. \& Vikhrov, A. (2000). Squeeze casting: an overview, Journal of Materials Processing Technology. 101(1), 1-9.

[4] Yue, T.M. \& Chadwick, G.A. (1996). Squeeze casting of light alloys and their composites. Journal of Materials Processing Technology. 58(2), 302-307.

[5] Britnell, D.J. \& Neailey, K. (2003). Macrosegregation in thin walled castings produced via the direct squeeze casting process. Journal of Materials Processing Technology. $138(1), 306-310$.

[6] Krishna, P. (2001). A study on interfacial heat transfer and process parameters in squeeze casting and low pressure 
permanent mold casting. Ph.D. Thesis, University of Michigan.

[7] Rajagopal, S. \& Altergott, W.H. (1985). Quality control in squeeze casting of aluminium. AFS Transactions. 93, 145154.

[8] Yang, L.J. (2007). The effect of solidification time in squeeze casting of aluminium and zinc alloys. Journal of Materials Processing Technology. 192, 114-120.

[9] Hu, H. (1998). Squeeze casting of magnesium alloys and their composites. Journal of Materials Science. 33(6), 15791589.

[10] Chattopadhyay, H. (2007). Simulation of transport processes in squeeze casting. Journal of Materials Processing Technology. 186(1), 174-178.

[11] Yue, T.M. (1997). Squeeze casting of high-strength aluminium wrought alloy AA7010. Journal of Materials Processing Technology. 66(1), 179-185.

[12] Raji, A. \& Khan, R.H. (2006). Effects of pouring temperature and squeeze pressure on $\mathrm{Al}-8 \% \mathrm{Si}$ alloy squeeze cast parts. $A U J T$. 9(4), 229-237.

[13] Yang, L.J. (2003). The effect of casting temperature on the properties of squeeze cast aluminium and zinc alloys. Journal of Materials Processing Technology. 140(1), 391396.

[14] Hong, C.P., Lee, S.M. \& Shen, H.F. (2000). Prevention of macrodefects in squeeze casting of an Al-7 wt. pct Si alloy. Metallurgical and Materials Transactions B. 31(2), 297-305.

[15] Benguluri, S., Vundavilli, P.R., Bhat, R.P. \& Parappagoudar, M.B. (2011). Forward and reverse mappings in metal casting - A step towards quality casting and automation (11009). AFS Transactions. 119, 19.

[16] Souissi, N., Souissi, S., Niniven, C.L., Amar, M.B., Bradai, C. \& Elhalouani, F. (2014). Optimization of squeeze casting parameters for 2017 a wrought al alloy using Taguchi method. Metals. 4(2), 141-154.

[17] Patel, G.C.M., Krishna, P. \& Parappagoudar, M.B. (2014). Optimization of squeeze cast process parameters using Taguchi and grey relational analysis. Procedia Technology. $14,157-164$.

[18] Senthil, P. \& Amirthagadeswaran, K.S. (2012). Optimization of squeeze casting parameters for non symmetrical AC2A aluminium alloy castings through Taguchi method. Journal of Mechanical Science and Technology. 26(4), 1141-1147.

[19] Senthil, P. \& Amirthagadeswaran, K.S. (2014). Experimental study and squeeze casting process optimization for high quality AC2A aluminium alloy castings. Arabian Journal for Science and Engineering. 39(3), 2215-2225.

[20] Vijian, P. \& Arunachalam, V.P. (2006). Optimization of squeeze cast parameters of LM6 aluminium alloy for surface roughness using Taguchi method. Journal of Materials Processing Technology. 180(1), 161-166.

[21] Vijian, P., Arunachalam, V.P. \& Charles, S. (2007). Study of surface roughness in squeeze casting LM6 aluminium alloy using Taguchi method. Indian Journal of Engineering \& Materials Sciences. 14, 7-11.

[22] Vijian, P. \& Arunachalam, V.P. (2007). Modelling and multi objective optimization of LM24 aluminium alloy squeeze cast process parameters using genetic algorithm. Journal of Materials Processing Technology. 186(1), 82-86.
[23] Guo, Z.H., Hou, H., Zhao, Y.H. \& Qu, S.W. (2012). Optimization of AZ80 magnesium alloy squeeze cast process parameters using morphological matrix. Transactions of Nonferrous Metals Society of China. 22(2), 411-418.

[24] Bin, S.B., Xing, S.M., Zhao, N. \& Li, L. (2013). Influence of technical parameters on strength and ductility of AlSi9Cu3 alloys in squeeze casting. Transactions of Nonferrous Metals Society of China. 23(4), 977-982.

[25] Patel, G.C.M., Krishna, P. \& Parappagoudar, M.B. (2015). Modelling of squeeze casting process using design of experiments and response surface methodology, International Journal of Cast Metals Research. 28(3), 167-180.

[26] Rao, R.V., Savsani, V.J. (2012). Mechanical design optimization using advanced optimization techniques, London: Springer.

[27] Rosenberg, R.S. (1967). Simulation of genetic populations with biochemical properties. Ph.D. Thesis, University of Michigan.

[28] Schaffer, J.D. (1985). Multiple objective optimization with vector evaluated genetic algorithm. In Proceedings of 1st International Conference on Genetic Algorithms, 93-100.

[29] Kuriakose, S. \& Shanmugam, M.S. (2005). Multi-objective optimization of wire-electro discharge machining process by non-dominated sorting genetic algorithm. Journal of Materials Processing Technology. 170, 133-141.

[30] Vundavilli, P.R., Kumar, J.P. \& Parappagoudar, M.B. (2013). Weighted average-based multi-objective optimization of tube spinning process using non-traditional optimization techniques. International Journal of Swarm Intelligence Research. 4(3), 42-57.

[31] Surekha, B., Kaushik, L.K., Panduy, A.K., Vundavilli, P.R. \& Parappagoudar, M.B. (2012). Multi-objective optimization of green sand mould system using evolutionary algorithms. The International Journal of Advanced Manufacturing Technology. 58(1-4), 9-17.

[32] Saravanan, R. \& Sachithanandam, M. (2001). Genetic algorithm (GA) for multivariable surface grinding process optimisation using a multi-objective function model. The International Journal of Advanced Manufacturing Technology. 17(5), 330-338.

[33] Rao, R.V., Pawar, P.J. \& Shankar, R. (2008). Multi-objective optimization of electrochemical machining process parameters using a particle swarm optimization. Proceedings of the Institution of Mechanical Engineers, Part B, Journal of Engineering Manufacture. 222, 949-958.

[34] Datta, R., Majumder, A. (2010). Optimization of turning process parameters using multi-objective evolutionary algorithms. In: Proceedings of the IEEE Congress on Evolutionary Computation, Barcelona, (July 2010). 38, 1-6.

[35] Ali-Tavoli, M., Nariman-Zadeh, N., Khakhali, A. \& Mehran, M. (2006). Multi-objective optimization of abrasive flow machining process using polynomial neural networks and genetic algorithms. Machining Science Technology: An International Journal. 10(4), 491-510.

[36] Agrawal, R.K., Pratihar, D.K. \& Choudhury, A.R. (2006). Optimization of CNC isoscallop free form surface machining using a genetic algorithm. International Journal of Machine Tools and Manufacture. 46(7), 811-819. 
[37] Navalertporn, T. \& Afzulpurkar, N.V. (2011). Optimization of tile manufacturing process using particle swarm optimization. Swarm and Evolutionary Computation. 1(2), 97-109.

[38] Zhou, A., Qu, B.Y. Li, H., Zhao, S.Z., Suganthan, P.N. \& Zhang, Q. (2011). Multi-objective evolutionary algorithms: A survey of the state of the art. Swarm and Evolutionary Computation. 1(1), 32-49.

[39] Das, S., Maity, S., Qu, B.Y. \& Suganthan, P.N. (2011). Realparameter evolutionary multimodal optimization-A survey of the state-of-the-art. Swarm and Evolutionary Computation. 1(2), 71-88.

[40] Patel G.C.M., Krishna, P., Parappagoudar, M.B. \& Vundavilli, P.R. (2016). Multi-objective optimization of squeeze casting process using evolutionary algorithms,
International Journal of Swarm Intelligence Research,7(1), 57-76. DOI: 10.4018/IJSIR.2016010103.

[41] Linder, J., Axelsson, M. \& Nilsson, H. (2006). The influence of porosity on the fatigue life for sand and permanent mould cast aluminium. International Journal of Fatigue. 28(12), 1752-1758.

[42] Abido, M.A. (2001). Particle swarm optimization for multimachine power system stabilizer design. In Power Engineering Society Summer Meeting, 2001 (3, 1346-1351). IEEE.

[43] Raquel, C.R. \& Naval, P.C. Jr. (2005). An effective use of crowding distance in multiobjective particle swarm optimization. Proceedings of the 2005 conference on Genetic and evolutionary computation, ACM, 257-264. 